\title{
BCG Moreau Rio de Janeiro - An oral vaccine against tuberculosis - Review
}

\section{Thereza Christina Benévolo-de-Andrade, Renata Monteiro-Maia*, Catherine Cosgrove**, Luiz Roberto R Castello-Branco/*}

\author{
Laboratório de Imunologia Clínica, Departamento de Imunologia, Instituto Oswaldo Cruz- Fiocruz, Av. Brasil 4365, 21045-900 \\ Rio de Janeiro, RJ, Brasil *Centro de Pesquisas Arlindo de Assis, Fundação Ataulpho de Paiva, Rio de Janeiro, RJ, Brasil \\ **Division of Infectious Diseases, St. George's Hospital Medical School, London, UK
}

\begin{abstract}
The vaccine Bacillus of Calmette Guérin (BCG) was originally developed in France as an oral vaccine against tuberculosis. The oral use of this vaccine was replaced by the parenteral route in almost all countries after the Lubeck disaster. In contrast, Brazil retained the oral delivery of the vaccine until the mid-seventies when it was replaced by the intradermal route. This change in route of delivery was mainly secondary to pressure by medical practitioners based on the poor responses of oral immunized subjects to purified protein derivative (PPD) skin tests. Even after the change of route of delivery, Ataulpho de Paiva Foundation continued making the oral vaccine. Currently, BCG Moreau has been described as one of the most immunogenic and with fewer side effects than other BCGs. The genomics, proteomics and vaccine trials for oral BCG Moreau Rio de Janeiro are currently under investigation. In this review, we intend to describe the history of BCG Moreau Rio de Janeiro in Brazil.
\end{abstract}

Key words: BCG Moreau Rio de Janeiro - oral vaccine - review

Vaccine BCG - Historical

The vaccine Bacillus of Calmette Guérin (BCG), used in the prevention of tuberculosis, was developed by two researchers, Albert Calmette and Camille Guérin, as an attempt to obtain homogeneous suspensions (without clumping) in the cultures of a very virulent bacillus, $M y$ cobacterium bovis, isolated by Nocard from a heifer with mastitis in 1902 (Sakula 1983), in the Pasteur Institute of Paris. In the Pasteur Institute of Lille, Calmette, accidentally obtained a mutated organism, after passages in vitro of the sample of $M$. bovis by cultivating the cultures in potatoes impregnated in ox bile, and Guérin, his assistant, observed, after 231 passages in vitro of the sample of $M$. bovis, during 13 years, alterations in the morphology of the colonies and gradual loss of virulence. These cultures did not lose the clumped morphology, and they maintained the same physical properties and displayed continued immunogenicity in animal experiments, using chimpanzees, guinea pigs, mice, and cattle (Succi 1985). That sample of bacilli was baptized with the name BCG-Bacillus of Calmette and Guérin, and successfully used in the active immunization of cows, without producing disease (Sakula 1983).

On June 21, 1921, the vaccine BCG was used for the first time in humans. At the request of a French doctor, who wanted to protect a newborn child, whose mother died of tuberculosis a few hours after the childbirth, and who would have to live with the grandmother, who also had tuberculosis. Calmette administered the culture of the bacillus (BCG vaccine), orally in three doses of $2 \mathrm{mg}$, soon

Corresponding author. E-mail: branco@ioc.fiocruz.br Received 22 February 2005

Accepted 4 July 2005 after the birth (Succi 1985). The child was reviewed for six months and did not show any sign of tuberculosis (Lagrange 1998). One semester after that first immunization, between 1921 and 1924, approximately another 300 children were vaccinated by the same researchers (Assis 1932).

In 1924, after demonstration of the safety of the vaccine, Calmette decided to increase the total dose of BCG to $30 \mathrm{mg}$ divided in three doses of $10 \mathrm{mg}$ delivered in the same way. Calmette chose the oral route for his studies, as the gastrointestinal tract is the natural route for infection by M. bovis. Weill-Hallé then tried the cutaneous and subcutaneous routes in other children, but local reactions to the injections caused them to be rejected by the children's relatives and the oral route continued to be the route used for immunization, with an emulsion prepared by Boquet and Negre. In 1924, they described a series of 664 oral immunizations in babies. The Pasteur Institute in Lille began to mass-produce the $\mathrm{BCG}$ vaccine for medical use. Between 1924 and 1928, another 114,000 children were immunized without serious complications (Sakula 1983).

Later on, the vaccination program widened to include adults, but this time the BCG was given subcutaneously, and in considerably smaller doses. This vaccination method began in France, in 1924, and had wide acceptance in the Scandinavian countries. Subcutaneous immunization also produced positive results to the tuberculin skin test in about $90 \%$ of the cases, unlike the $40 \%$ obtained with oral immunization (Ataulpho de Paiva Foundation's files).

During the years of 1924 to 1926 , nurses of the Ulleval Hospital, in Oslo (Norway) observed that the oral administration of BCG failed to produce allergic response and, in agreement with the incorrect hypothesis that the cuta- 
neous tissue is an important source of antibodies, they decided to apply the vaccine parenterally via the subcutaneous route. The vaccine was then given to two "nonallergic" (naive) individuals, who became positive to the cutaneous tuberculin test six weeks after the inoculation of the antigen. It became evident that BCG was not deleterious and that parenteral administration could enable "allergic" reaction to the PPD (purified protein derivative), or tuberculin skin test, one of the criteria accepted as evidence of immunity against tuberculosis (Heimbeck 1948).

Consequently, the intradermic route became popular, especially after 1927 , when Wallgreen perfected the intradermic vaccination, inoculating $0.1 \mathrm{mg}$ of BCG in individuals of any age, negative to the skin test.

Aiming to reduce the local reactions, other immunization routes were developed, parenteral introduced by Rosenthal and scarification, by Negre and Brettey. These innovations were based upon the fast and durable emergence of the "tuberculosis allergy", as a positive test of the protective efficacy of vaccination with BCG. Oral immunization was little by little being abandoned by most countries (Ataulpho de Paiva Foundation's files).

After the presentation of their results to the National Academy of Medicine in Paris, the Pasteur Institut of Lille was authorized to distribute samples of the bacillus to other laboratories all over the world. Between 1924 and 1926, at least 34 countries received the culture of BCG from the Pasteur Institute and, in 1927, another 26 countries received cultures of BCG (Oettinger et al. 1999).

During the years of 1921 to 1927 , Calmette reported that other children, born to mothers with tuberculosis or whose mother had contact with the disease, were vaccinated with BCG and only $3.9 \%$ died from the infection. On the other hand, among the non-vaccinated children, the death rate from tuberculosis was $32.6 \%$ (Bloom \& Fine 1994). In 1928, the vaccine BCG became internationally accepted and mass vaccinations were started in France and Scandinavia.

However, in Lubeck, Germany, in 1930, a serious accident happened that caused profound changes in vaccination with BCG; 250 children were supposedly vaccinated with BCG and 73 died from tuberculosis in the first year, while another 135 developed signs and symptoms of disease (Sakula 1983). Subsequent investigations revealed that a culture of M. tuberculosis, isolated from a sick child, was kept in the same incubator with the BCG and, during the vaccine preparation, the vaccine became contaminated and contained $1 / 3$ of BCG and $2 / 3$ of the tuberculous bacillus (MS 1994). Calmette died in 1933, sad and discouraged after this incident in Germany. Still in the 1930s, the institutional incorporation of new technologies to prevent, diagnose, and treat tuberculosis was adopted, with BCG, microscopy, mass radiography, and thoracic surgery.

After the Second World War, the use of BCG increased in Europe and within the developing countries (Succi 1985). In 1966, as part of a WHO initiative the vaccine BCG started being lyophilized.

\section{The genealogy of BCG}

The full genome of BCG has been elucidated, 129 genes are absent from BCG that are present in M. tuberculosis. M. tuberculosis has a larger genome than M. bovis; 4.41 $\mathrm{Mb}$ versus $4.32 \mathrm{Mb}$ (Corbel et al. 2004). Recent molecular analysis has deduced that the primary deletion was most likely to be a $9.5 \mathrm{~kb}$ DNA segment, designated RD1, which has been found to be absent from all BCG strains but present in all virulent laboratory and clinical strains of $M$. bovis and M. tuberculosis tested so far. There have been 49 sub-strains in production and in use at one time or another (Corbel et al. 2004).

$\mathrm{RD} 2$, a $10.7 \mathrm{~kb}$ DNA segment, was found conserved in all virulent laboratory and clinical strains of $M$. bovis and tuberculosis, and was deleted only from BCG substrains derived from the BCG Pasteur strain after 1925. It is conserved in BCG Moreau which has its own specific deletion named RD16. RD3 is absent from all BCG strains and many clinical isolates of M. tuberculosis (Mahairas 1996).

From these molecular analyses and studies of their culture, two main groups of BCG have been suggested, BCG Tokyo, Moreau, Russia, and Sweden that have two copies of the insertion sequence ISI986, and contain methoxymycolate and the mpt 64 gene; BCG Pasteur, Copenhagen, Glaxo and Tice that have a single copy of the insertion sequence ISI986, do not contain methoxymycolate and the MPB64 gene (Ohara \& Jamada 2001). The genes for MPB70 and MPB83 are still present but not expressed in post-1927 sub-strains, which a recent WHO consultation feels may have implications for protective efficacy (Corbel et al. 2004). From these observations and the known sequence of worldwide distribution to various laboratories Behr et al. (1999) have proposed a historical genealogy of BCG (Fig. 1).

\section{BCG in Brazil}

In Brazil, from 1835, the medical speeches of the Imperial Academy in Rio de Janeiro (capital of the Republic) called attention for the high mortality rate caused by tuberculosis, which at that time was responsible for $14.4 \%$ of the deaths in the city (Ribeiro 1993).

Due to the increase in the cases of tuberculosis, a team of concerned citizens - medical doctors, politicians, and intellectuals who were convinced they should try fighting the disease which was causing so many deaths, founded, in Rio de Janeiro, in 4 August 1900, the Brazilian League against Tuberculosis, present Fundação Ataulpho de Paiva (FAP), the objective of which was to care for prophylaxis, to treat the disease and assist its victims support houses, pharmacies, and other activities (Ribeiro 1985). The League, then, developed an intense campaign against tuberculosis (Fig. 2).

On distribution of BCG vaccine samples by the Pasteur Institut, one sample arrived in Brazil, in 1925, brought by the Uruguayan doctor, Julio Elvio Moreau. That sample was delivered to the researcher Arlindo de Assis, in Rio de Janeiro and was called BCG Moreau. Even today, the reason why that sample was not taken to Uruguay is still unknown. 


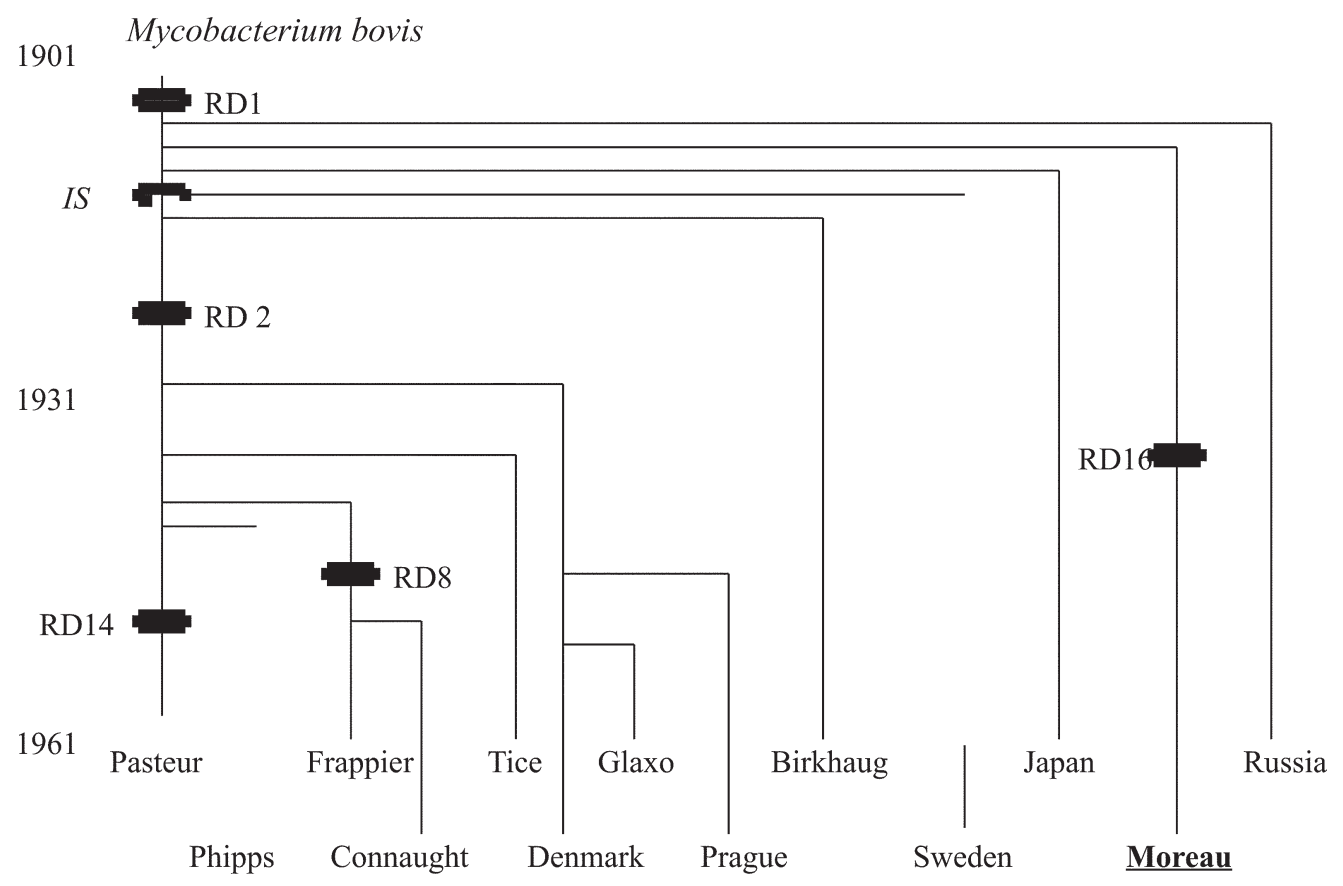

Fig. 1: BCG historical genealogy with the vertical axis representing time and the horizontal axis denoting different geographic locations of BCG propagation. RD: region of deletion. Note BCG Moreau does not have the regions of deletions 2, 8 or 14 and has its own unique RD16. Adapted from a figure by Behr 1999.

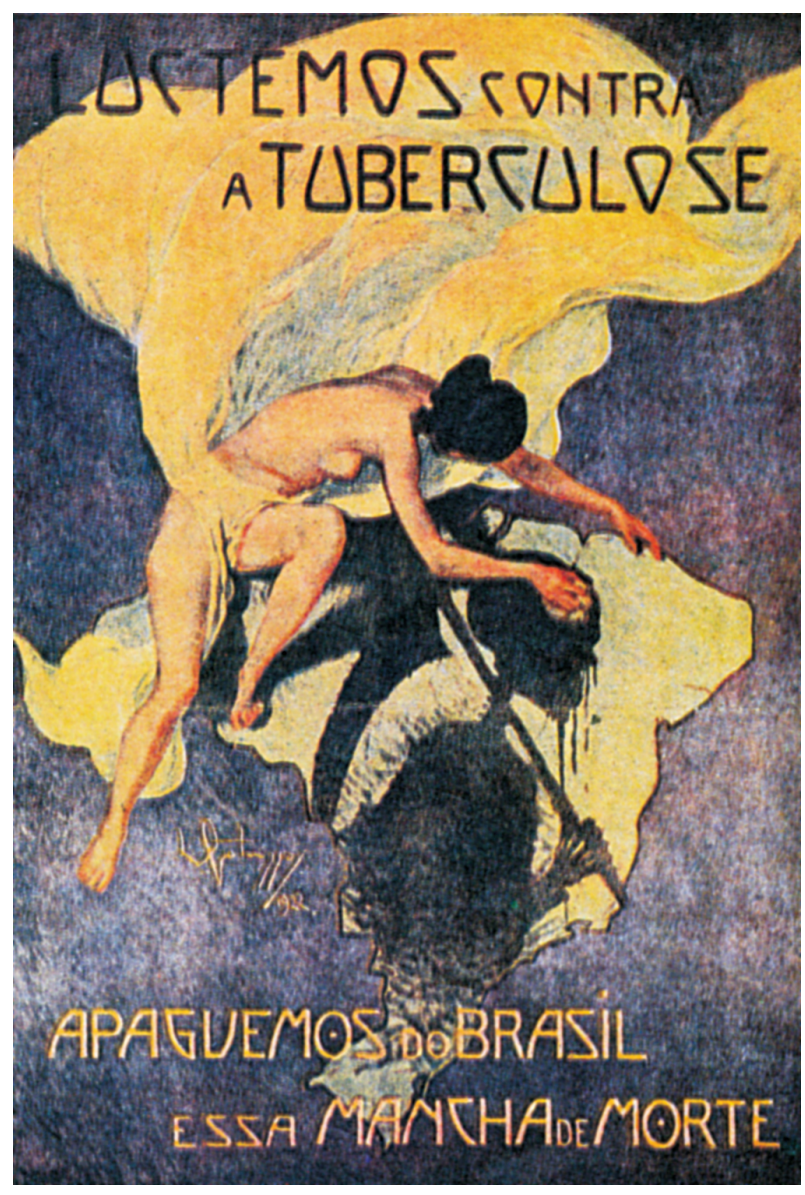

Fig. 2: poster of the campaign against tuberculosis.
Initially, the vaccine BCG was produced by Arlindo de Assis in the Vital Brazil Institute, in Niterói, until 1930, when he was invited by the Minister Ataulpho de Paiva, president of the Brazilian League against Tuberculosis, to continue with the production and experiments with the BCG vaccine in the League itself. Concerning the production and distribution of the vaccine BCG, the FAP played an important role. It is presently responsible for $5 \%$ of the whole world's production of BCG.

The history of BCG in the state of Rio de Janeiro, Brazil, cannot be told without mentioning the collaboration of Arlindo de Assis. José Rosemberg, doctor and pharmacist, describes Arlindo de Assis as "a great bacteriologist and the father of BCG in Brazil". Regarding the personality of Arlindo de Assis, Rosemberg points out his positioning towards the episode that happened in Lubeck; Arlindo insisted on the vaccination, affirming that the accident had been caused by a specific lot of the vaccine. Despite opposition, he continued with BCG vaccination in Brazil, a decision that was later proved to be right.

In 1929, three doses were given on alternate days during the first ten days after birth. Initially a total of $60 \mathrm{mg}$ of BCG was given but later, from 1940, $90 \mathrm{mg}$ was given (Assis 1950).

The immunization by BCG developed in 1944 more than in any of the previous years, in Brazil, due to the important performance of both the FAP and the National Service of Tuberculosis. Just in that year, about 19,000 babies were vaccinated with the oral BCG, which indicates how the vaccine had been accepted by society as a whole. Besides the newborn infants, the vaccination program was extended to the "non-allergic" individuals of other ages. 
To those individuals, $200 \mathrm{mg}$ of oral BCG used to be administered, always in the mornings, after an over night fast. By the end of 1944, the total "non-allergic" individuals immunized were approximately 2500 (Assis 1945a).

As well as immunizing the population of the Federal District (Rio de Janeiro), the FAP also had to supply other states, which did not have the means to produce the vaccine, so that, by the end of $1944,57,595$ ampoules of $30 \mathrm{mg}$ had been distributed by FAP and over 120,000 delivered by the National Service of Tuberculosis (Assis 1945a).

During the years of 1945-1946, 61 newly born children were immunized by the method called "recurrent $B C G$ vaccination", which consisted of the oral administration of $100 \mathrm{mg}$ each month, for six months. The first results of the new methodology were the absence of proven or even suspected tuberculosis mortality or morbidity; the reduction of infant mortality to $3.28 \%$; absence of abnormal radiological tests in the first 12 months; presence of $14.7 \%$ of radiographic images of transitory lymphadenopathy after the first year, coexisting with tuberculin allergy (medium or high) without clinical symptoms of tuberculosis (Assis 1950). Assis believed that such a vaccination program would increase the chances of preventing the disease in individuals who were in contact with tuberculosis (Assis 1950). The immunization practice allowed for safe contact between vaccinated individuals and tuberculosis patients without needing to isolate the patient with tuberculosis (Assis 1956).

This immunization schedule, however, brought some problems, mainly with mass campaigns due to the difficulties of repeating six doses, monthly or biweekly, in the same individuals of a population, without mentioning the increase in production in large scale by the specialized laboratories in order to supply the increased vaccine demand (Assis 1956). Thus, Assis (1956) decided that it would be better to immunize with only one dose (calmetization), both the urban and rural populations, as well as the individuals and families without contact with tuberculosis. On the other hand, the recurrent vaccination would be indicated for those groups in permanent contact with the infection. Then, the calmetization in mass would be restricted to the health centers, while the recurrent vaccination to the specialized areas of the anti-tuberculosis fight.

In 1947, it was decided to immunize neonates by oral administration of a single dose of $100 \mathrm{mg}$ BCG and, in "non-allergic" individuals, a single dose of $200 \mathrm{mg}$. In both cases, the positive response to the cutaneous test occurred (Ataulpho de Paiva Foundation's files).

After 1973, the intradermic route became the method used in national programs of vaccination against tuberculosis. In spite of that, the oral vaccination continued to be used in neonates until 1976 (Gerhardt et al. 1988). From 1977 on, the oral vaccination was no longer practiced routinely in health centers. The rules of the National Division of Sanitary Pneumology (DNPS) recommended, for newborns, half a dose $(0.05 \mathrm{ml})$ by intradermic route and then re-vaccination when at school age. That vaccine schedule continued until 1982, when a single dose was established $(0.1 \mathrm{ml})$ for neonates and the re-vaccination program was ended; that is until as a new re-vaccination program is currently being studied (Gerhardt et al. 1988).

\section{BCG and the delayed type hypersensitivity skin reaction to PPD}

In Brazil, the vaccine BCG was administered exclusively via the oral route until 1968, when nurses were trained to vaccinate children by using the same route as the skin test, i.e., intradermal route. The skin tests, as standardized by WHO as from 1952, had only been applied in Brazil in 1961, then, looking at all the comparable national and foreign data, it was shown that PPD should be used in a single and weak dose (CNCT 1968).

Studies performed by researchers at the Escola Paulista de Medicina strongly contributed to the change of immunization route, after they observed that individuals immunized with oral BCG would have a weak or no response to the cutaneous test, unlike those immunized with the intradermal route (Succi 1985). Economical and operational reasons also contributed to the abandonment of the oral route (Mortatti et al. 1987).

The poor response to the cutaneous test increased the doubts regarding the effectiveness of BCG vaccination. Debret demonstrated that the cutaneous reaction only appeared when high doses of tuberculin were administered by the intradermal route, while Assis produced evidence that, one month after the vaccination, $73 \%$ of the immunized children had a positive skin test (conference of Assis 1932). Assis and Carvalho (1940) observed that, one week after vaccinating 167 neonates with oral BCG, none of them had reacted positively to the cutaneous tests, but they became positive in $82.4 \%$ of the cases six weeks upon the vaccination. After that period, the increase in the reaction was not significant, reaching the maximum level between six and 12 months after vaccination. In the same study, Assis and Carvalho affirm that the allergy produced by oral immunization was as great as that caused by the parenteral route (subcutaneous, intracutaneous or intradermal). The absence of cutaneous response in $17.6 \%$ of the individuals vaccinated via the oral route was then considered by the authors as an individual's inability to mount an allergic response in general.

Another research accomplished by Arlindo de Assis and Alvimar de Carvalho, in 1940, studied the emergence of tuberculin allergy in most of the individuals immunized with oral BCG, neonates, and adults. They observed that the BCG vaccine, whenever administered in the neonates by the oral route, elicited specific hypersensitivity to the tuberculin in more than $80 \%$ of the cases. All the 4,389 children were selected in families exempt of virulent tuberculosis infection and examined in the clinic belonging to the BCG vaccination department of FAP. The study was performed with two months intervals in the course of the first two years of age.

Through the Fig. 3, they reached the conclusion that the vaccination method practiced in Rio de Janeiro, administering BCG by oral route, according to the standards followed by the Brazilian League against Tuberculosis, was effective in the newborn and produced a specific immunization to the vaccinated organisms. The authors concluded that such "alergization" had its own characteristics, which turned to be different from the "alergization" produced in the youth by the infection with the tubercu- 


\section{Variações de positividade da alergia tuberculinica observadas de 1928 a 1939, em 4.389 crianças de familias șem tubereulose $e$ orovacinadas, com B.C.乌., ao nascer no Rio de Janeiro, pela Fundaẹão Ataulpho de Paiva.}

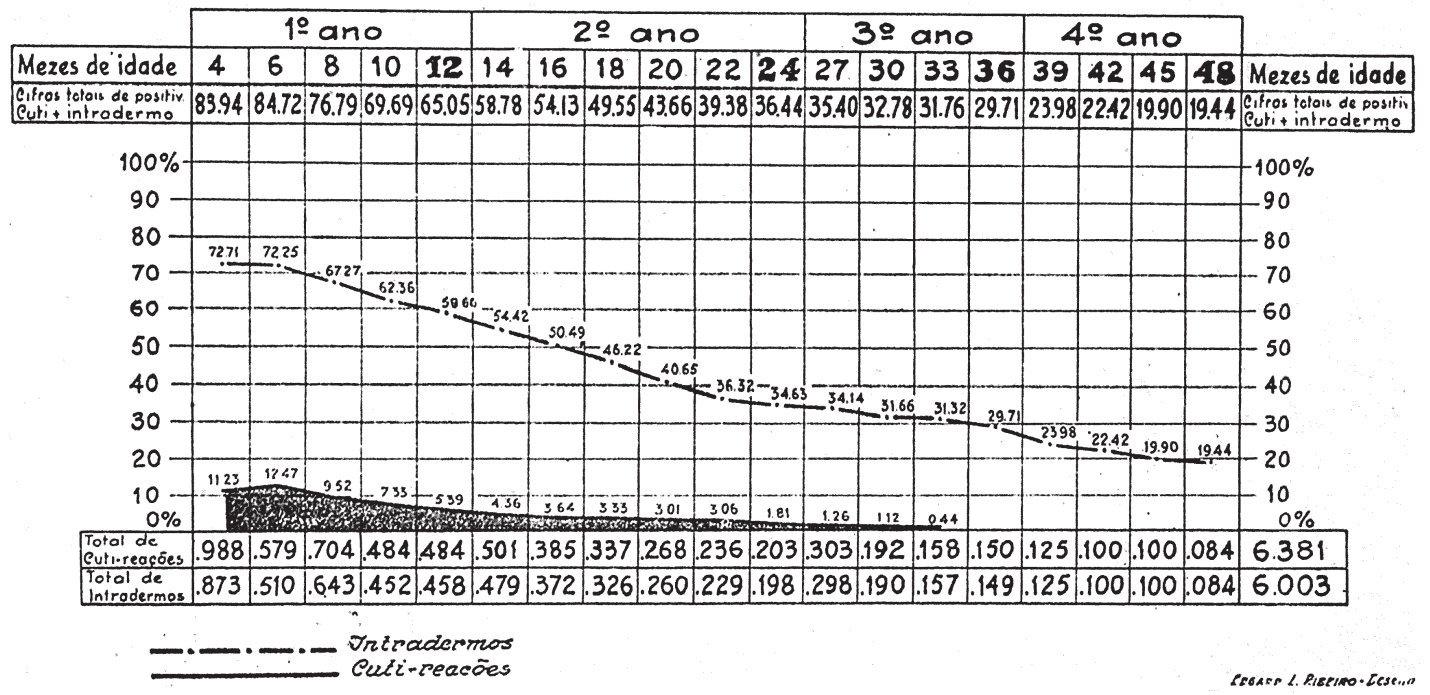

Fig. 3: skin tests in orally immunized neonates - 48 month follow-up. This 1940 graph shows variations on positive skin tests (mean $70 \%$ after immunization and $20 \%$ four years later) observed in 4389 children belonging to tuberculosis free families and vaccinated with oral BCG on birth, in Rio de Janeiro. This graph is the faithful copy of the original

lous bacillus (Assis \& Carvalho 1940). That tuberculin allergy specifically produced by oral BCG presents well defined characters, being almost always moderate and regressive (Assis 1950).

\section{Tolerance to BCG}

Another very interesting study by Arlindo de Assis is the one that aimed to investigate the effects of the continuous use of really high doses of BCG in humans, with a positive tuberculin skin test, not for immunization purposes, but in order to verify that oral BCG had no effect on patients with evidence of prior tuberculous exposure. For such, two volunteers, the author himself and his assistant, submitted themselves to vaccination with oral BCG. Neither had tuberculosis disease, but they reacted to the tuberculin skin test and had radiographic features of residual tuberculosis prime-infection. The experiment consisted of the ingestion of a live suspension of BCG, after an overnight fast and then being nil-by-mouth for $1 \mathrm{~h}$ after the ingestion of the BCG. Such ingestions were daily, non-stop, for consecutive months, with some modifications in one of the cases, i.e., daily doses went progressively increasing from $4.5 \mathrm{mg}$ up to $30 \mathrm{mg}$. We should point out that such rates were much higher than the ordinary use for the tuberculosis prevention at that time. Finally, the use of BCG stopped, while both the tuberculin skin test and radiological investigations continued (Assis 1945b).

Parallel to the clinical health check-ups, radiographic tests were made and were unaffected (nothing abnormal appeared), tuberculin tests had a degree of attenuation resulting from the daily use of BCG. Haematological tests (white blood cell counts and determination of sedimentation speed) showed only a discreet tendency to relative lymphocytosis, without well-defined characteristics. There was no direct evidence of BCG causing any damage to the two volunteers' health, either during or after having finished the experiment (16 and 10 months, respectively, for each one). It was felt to be that the doses supplied, despite being high and of long lasting use, as well as with radiological evidence of prime-infection, produced immune modulation and decreased hypersensitivity, demonstrated by the decrease in the tuberculin skin reactions (Assis 1945a) (Fig. 4).

No direct effect arising from the use of the Calmette bacillus harmed the two volunteers' health, who received, during the course of the research, over $2 \mathrm{~g}$ of $\mathrm{BCG}$ doses. During and after having finished the experience (16 and 10 months, respectively for each one) several X-rays were done during the immunizations and they were unchanged. This study showed that the allergic adult without active tuberculosis, tolerates BCG administered by the digestive route in doses rather superior than those which had been used until that moment, proving BCG to be perfectly innocuous and unable of mobilizing the old lesions of prime-infection (Assis 1945a).

In 1945 , the high mortality by tuberculosis in the 1 st year of life of new born children that lived with individuals with pulmonary tuberculosis, forced Arlindo de Assis to develop a new vaccination program with BCG for 62 newly born from Rio of Janeiro who remained exposed to tuberculosis patients from their first days of life, and without possibility of segregation. The follow up continued until the babies' 2nd year of life. The schedule, named 


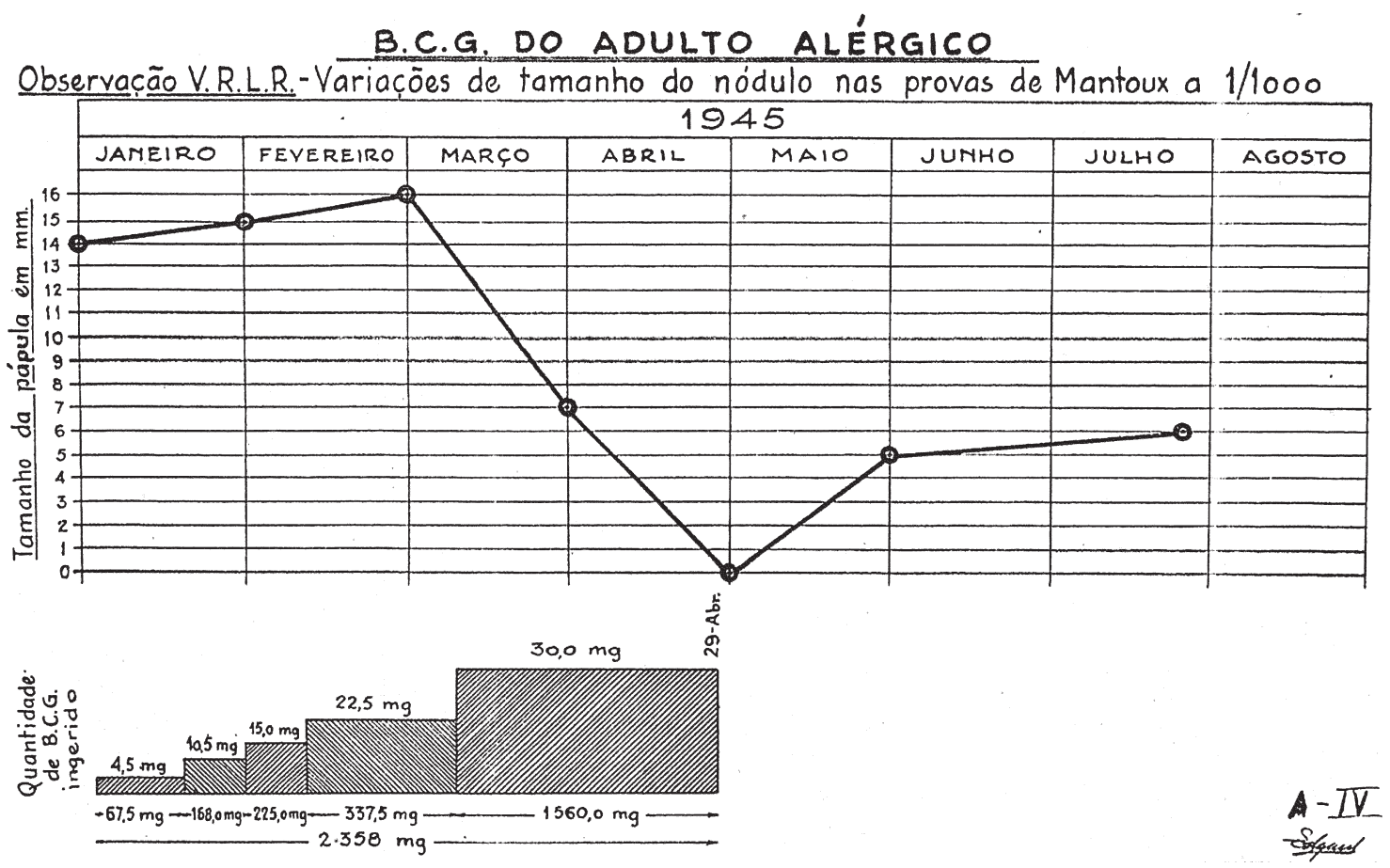

Fig. 4: oral BCG Moreau Rio de Janeiro modulates the size of the Mantoux skin test $(0.1 \mathrm{mg})$. This 1945 graph shows the correlation of Mantoux skin test size in millimeters before and after oral BCG Moreau de Janeiro vaccination in one volunteer. The volunteer was studied from January to July. The amount of BCG ingested (partial and total) from January to April is shown in the bottom graph. This graph is the faithful copy of the original

"Recurrent BCG vaccination", foresaw the administration of BCG after birth, followed by re-vaccinations every month during six months. The prime-immunization was with three doses of $30 \mathrm{mg}$ on intervals of two to three days, starting from the 1st week of life. The re-vaccinations were made with a single dose of $100 \mathrm{mg}$, every month up to six months of life. In such conditions, the children had ingested about $600 \mathrm{mg}$ of BCG during the first semester of life, precisely in the period of major susceptibility to the infection (Assis 1947).

The early recurrent vaccination of infants to their 6 th month of life showed that, despite the permanent postbirth contact, no death from tuberculosis was observed in any of the 61 cases over four years. None of the vaccinated children presented proven prime-bacteriological tuberculosis and only nine showed radiological signs of suspected tuberculosis infection, without clinical symptoms of the disease (Assis 1949).

Arlindo de Assis died in 1966, but the use of oral immunization persisted until today, as some physicians still prescribe this kind of immunization and FAP makes some 10,000 doses of this vaccine per year. New studies on the genomics and proteomics of this strain (BCG Moreau Rio de Janeiro) are being carried out in between FAP and Fundação Oswaldo Cruz. A phase I clinical trial has just finished at the St. George's Vaccine Centre (London, UK) with an oral BCG Moreau Rio de Janeiro vaccine and the results suggest that this vaccine is very immunogenic and no serious side effects were demonstrated (Cosgrove 2005, unpub. data).

\section{ACKNOWLEDGEMENTS}

To Katia Maria de Mattos for reviewing the manuscript.

\section{REFERENCES}

Assis A 1932. Estado actual da vaccinação antituberculose pelo BCG no Rio de Janeiro. Conferência realizada em 5 de janeiro de 1932 na Liga Brasileira contra a Tuberculose. Officinas Graphicas do Jornal do Brasil, Rio de Janeiro.

Assis A 1945a. A vacina BCG no Brasil em 1944. O Hospital XXVII: 187-193.

Assis A 1945b. Tolerância do organismo adulto-alérgico ao BCG. O Hospital XXVIII: 875-898.

Assis A 1947. Vacinação BCG concurrente. O Hospital XXXI: 814-822.

Assis A 1949. Bases do controle da vacinação BCG no Brasil e sua evolução. O Hospital XXXVI: 309-318.

Assis A 1950. Novas perspectivas da vacinação contra a tuberculose pelo BCG. O Hospital XXXVIII: 337-353.

Assis A 1956. Posição atual do método brasileiro de vacinação BCG na prevenção da tuberculose. O Hospital XLIX: 1-14.

Assis A, Carvalho A 1940. Vacinação BCG por via bucal e alergia tuberculínica. O Hospital XVIII: 543-553.

Behr MA, Wilson MA, Salamon H, Schoolnick GK, Rane S, Smael PM 1999. Comparative genomics of BCG vaccines by whole-genome DNA microarray. Science 284: 1520-1523.

Bloom BR, Fine PEM 1994. The BCG experience: implications for future vaccines against tuberculosis. In Tuberculosis: 
Pathogenesis, Protection and Control, American Society for Microbiology, Washington, p. 531-557.

CNCT-Comissão Técnica da Campanha Nacional contra a Tuberculose 1968. Prova tuberculínica em Saúde Pública (2 $2^{\mathrm{a}}$ recomendação). Rev Serv Nac Tuberculose 12: 219-230.

Corbel MJ, Fruth U, Griffiths E, Kneizevic I 2004. Report on a WHO consultation on the characterisation of BCG strains, Imperial College, London 15-16, 2003. Vaccine 22: 26752680.

Gerhardt GF, Teixeira GM, de Lima MAR, Cunha IH, de Macedo EA, Nunes AP 1988. Estudo comparativo de respostas de duas vacinas BCG em crianças de zero a dois meses. Bol CNCT 2: 5-13

Heimbeck J 1948. BCG vaccination of nurses. Tubercle, April: 84-88.

Lagrange PH 1998. Vaccination antituberculeuse par le BCG: historique d'une découverte et de sés controverses. Médicin Sciences 14: 314-319.

Mahairas GG, Sabo PJ, Hickey MJ, Singh DC, Stover CK 1996. Molecular analysis of genetic differences between Mycobacterium bovis BCG and virulent $M$. bovis. J Bacteriol 178: $1274-1282$.

Mortatti RC, Maia LCS, Fonseca LS 1987. Absorption of
Mycobacterium bovis BCG administered by the oral route. Vaccine 5: 109-114.

MS - Ministério da Saúde 1994. Segundo Informe Técnico sobre Vacinação/revacinação BCG, Fundação Nacional de Saúde, Centro Nacional de Epidemiologia, Coordenação Nacional de Pneumologia Sanitária, Brasília, 56 pp.

Oettinger T, Jorgensen M, Ladefofed A, Haslov K, Andersen P 1999. Development of the Mycobacterium bovis BCG vaccine: review of the historical and biochemical evidence for a genealogical tree. Tubercle and Lung Dis 7: 243-250.

Ohara N, Yamada T 2001. Recombinant BCG vaccines. Vaccine $19: 4089-4098$

Ribeiro L 1985. Ataulpho de Paiva Foundation: Liga Nacional Contra a Tuberculose - Notas e documentos para a sua história. Rio de Janeiro, 372 pp.

Ribeiro SN 1993. O controle da tuberculose no Brasil: principais momentos de sua história. Pulmão (RJ) 3: 27-39.

Sakula A 1983. BCG: Who were Calmette and Guérin? Thorax 38: 9-6-812.

Succi RCM 1985. BCG. In CK Farhat, Fundamentos e Prática das Imunizações em Clínica Médica e Pediatria, Atheneu, Rio de Janeiro, p. 27-41. 